\title{
Stroke risk and critical carotid stenosis
}

\author{
J W Norris, C Z Zhu
}

\begin{abstract}
The risk of stroke from carotid stenosis is proportionate to the degree of stenosis, but whether this is a direct and linear relationship is unknown. Using the degree of carotid stenosis in 500 patients with asymptomatic carotid bruits as a continuous variable, we plotted the frequency distribution and related this to the risk of ischaemic cerebral events and the progression of the arterial lesion. There was a bi-modal distribution, with the junction of the two populations at $85 \%$ stenosis. The frequency of ischaemic cerebral events was maximal at $75-90 \%$ stenosis. Our data suggest that there is a critical degree of carotid stenosis at which stroke risk becomes maximal. This may represent a window of therapeutic opportunity.
\end{abstract}

The relationship between stroke risk and extracranial carotid stenosis was first suggested by Miller Fisher ${ }^{1}$ but the hierarchy of this risk with increasing severity of the carotid lesion was only established more recently. ${ }^{2-4}$ However, the risk of stroke falls once the artery occludes, ${ }^{5}$ suggesting that this relationship is not linear and that there is a critical degree of carotid stenosis where stroke risk is maximal. This concept has important, practical applications in the medical and surgical management of patients with carotid arterial disease.

To examine this correlation, we investigated the frequency distribution of carotid stenosis in a group of asymptomatic patients, relating it to the subsequent outcome of ischaemic cerebral and cardiac events.

\section{Materials and methods}

This study was based on the clinical and carotid Doppler findings in 500 patients with asymptomatic cervical bruits, prospectively and systematically followed up over a mean time of 52 months. ${ }^{4}$

Continuous-wave directional Doppler ultrasound examination was performed with a $5 \mathrm{mHz}$ probe, using a colour coded spectral analyser (Carolina Medical Electronics 1050). The probe was placed on the neck at a 60 degree angle recording the maximum peak Doppler shifted frequencies. Doppler peak frequencies in $\mathrm{kHz}$ were previously compared in our laboratory to conventional bi-plane angiograms, where we found a Pearsons correlation coefficient ( $r$ ) of $0.91 .^{6}$ Using a quadratic regres- sion model to compare Doppler $\mathrm{kHz}$ to angiographic peak stenosis, there was a highly significant correlation, $\mathrm{p}<0.0001 .^{7}$

At subtotal stenosis $(>95 \%)$ this linear relationship declines and the distinction between total and subtotal occlusion is less certain. However, even at this level, we found a specificity of $95-99 \%$, sensitivity of $86-96 \%$ and accuracy of 95-98\%, when Doppler shift was compared to standard or digital subtraction angiography. ${ }^{7}$

Clinical cerebral and cardiac events were collected prospectively at each six monthly evaluation, and where necessary, coroners' reports, hospital records and other medical information were also documented. These events were then categorised according to the degree of carotid stenosis on entry into the study. Chi-squared tests and analysis of variance (ANOVA) were used to compare groups.

\section{Results}

Among the 500 patients in the initial cohort, there were 51 carotid ischaemic events during the follow up period consisting of 40 TIAs and 11 ischaemic strokes. Vertebro-basilar events were not included in the analysis. Significantly more carotid ischaemic cerebral events occurred in patients with carotid stenosis of 75$90 \%(p<0.0001)$ than in those with arterial lesions of lower or higher degrees of stenosis (fig 1, table 1).

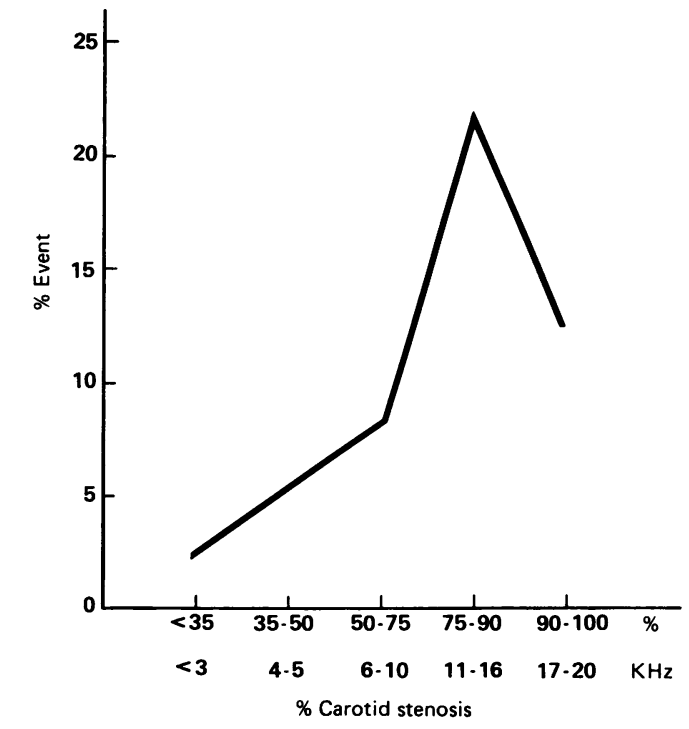

Figure 1 Distribution of ischaemic cerebral events according to severity of carotid stenosis. 
Table 1 Distribution of carotid ischaemic events (TIAs and strokes) according to severity of carotid stenosis in 1000 arteries ( 500 patients). Percentage stenosis is equated to Doppler $\mathrm{KHz}$.

\begin{tabular}{|c|c|c|c|c|c|}
\hline \multirow[b]{2}{*}{ Group } & \multicolumn{5}{|c|}{ Severity of carotid stenosis } \\
\hline & $\begin{array}{l}<35^{\circ}{ }^{o} \\
(0-3 K h Z)\end{array}$ & $\begin{array}{l}35-50^{\circ} \\
(4-5)\end{array}$ & $\begin{array}{l}50-75 \% \\
(6-10)\end{array}$ & $\begin{array}{l}75-90 \% \\
(11-16)\end{array}$ & $\begin{array}{l}90-100 \% \\
(17-20)\end{array}$ \\
\hline $\begin{array}{l}\text { Events } \\
\text { No events }\end{array}$ & $\begin{array}{r}14 \\
586\end{array}$ & $\begin{array}{r}7 \\
127\end{array}$ & $\begin{array}{r}14 \\
158\end{array}$ & $\begin{array}{l}10^{\star} \\
36\end{array}$ & $\begin{array}{r}6 \\
42\end{array}$ \\
\hline Total arteries & 600 & 134 & 172 & 46 & 48 \\
\hline
\end{tabular}

\begin{tabular}{|c|c|c|c|c|}
\hline Group & $n$ & Follow up (mos) & $\begin{array}{l}\text { Progression } \\
\text { Entry Doppler }(\mathrm{KHz}) \\
\text { mean }(S D)\end{array}$ & $\begin{array}{l}\text { Final Doppler }(\mathrm{KHz}) \\
\text { mean }(S D)\end{array}$ \\
\hline $\begin{array}{l}\text { Carotid events } \\
\text { Cardiac events } \\
\text { Control }\end{array}$ & $\begin{array}{l}51 \\
67 \\
46\end{array}$ & $\begin{array}{l}21 \cdot 4 \\
19 \cdot 0 \\
20 \cdot 8\end{array}$ & $\begin{array}{l}9 \cdot 1(5 \cdot 9) \\
7 \cdot 2(6 \cdot 0) \\
6 \cdot 5(6 \cdot 6)\end{array}$ & $\begin{array}{l}14 \cdot 3(6 \cdot 0) \dagger \\
9 \cdot 6(7 \cdot 1) \\
6 \cdot 9(6 \cdot 8)\end{array}$ \\
\hline
\end{tabular}

*Change in mean $\mathrm{KHz}$ during follow up.

$+\mathrm{p}<0.0001$ (ANOVA).

Progression of carotid stenosis was compared in these 51 patients with cerebral events and in 67 patients developing ischaemic cardiac events over the follow up period. A further 46 patients with asymptomatic carotid bruits, matched for age and sex, who remained asymptomatic throughout the study, were used as controls. Mean per cent stenosis $(\mathrm{kHz})$ at entry and duration of follow up was not significantly different in any group (table 2). Patients with carotid TIAs or strokes showed significantly more progression of their carotid stenoses than controls or than those with cardiac events $(\mathrm{p}<0.0001)$

A frequency distribution curve was then constructed using only arteries with Doppler evidence of carotid stenosis. There were 254 patients (400 arteries), mean age 64.5 years, composed of 134 women and 120 men. Over the follow up period, 13 patients (19 arteries with carotid stenosis) were either lost from the analysis due to carotid surgery, lost to follow up, or had died; this left $\mathbf{3 8 1}$ arteries for final analysis from the initial 400 . Frequency analysis showed a bi-modal distribution, with the junction between the two groups at $15 \mathrm{kHz}$ (about $85 \%$ stenosis) (fig 2 ). The age and sex distribution of these two populations did not differ significantly.

Figure 2 Frequency distribution of asymptomatic carotid stenosis in 381 arteries at entry to study.

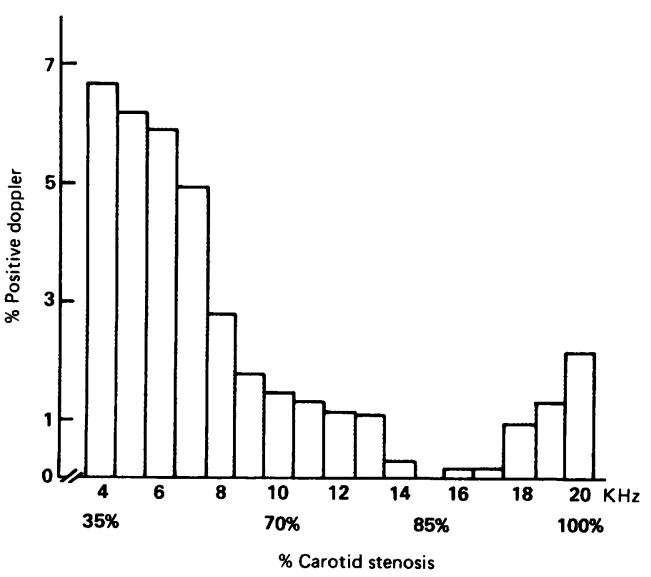

\section{Discussion}

The bi-modal distribution of carotid stenosis in our study cohort does not correspond to the anticipated theoretical frequency distribution of a continuous variable such as severity of the arterial lesion. It suggests the influence of something other than putative risk factors, which were equal in both populations. It is unlikely to be a chance finding since the only entry criterion was the presence of an asymptomatic neck bruit. The frequency distribution curve was plotted on the basis of asymptomatic carotid stenosis alone and so does not reflect the change in neck bruits as the artery stenoses. For the same reason, it is unlikely to represent "referral filter bias" or other factors which artificially skew the frequency distribution. ${ }^{8}$

The junction between the two populations at about $85^{\circ}$ o stenosis corresponds to the peak frequency distribution of ischaemic cerebral events in our patients (fig 1) and so is more likely to represent a "harvesting" effect. Patients developing TIAs or strokes at this degree will not enter our asymptomatic study cohort. This high risk sub-group $\left(75-90^{\circ}{ }_{0}\right.$ stenosis) experienced a $43^{\circ}{ }_{0}$ risk of carotid cerebral events over 52 months, but this risk fell precipitously once it passed the "critical" degree of stenosis. This is compatible with the concept that once the carotid artery occludes, stroke risk becomes minimal. ${ }^{5}$

A critical value of $80-85^{\circ} \%$ stenosis in the genesis of symptoms is supported by data from several other sources. Spencer and Reid constructed a flow model of the carotid bifurcation and showed that blood flow remains constant and blood velocity increases with progressive narrowing of the lumen up to about $80 \%$, at which point both decline precipitously. ${ }^{9}$ Haemodynamic compromise will not occur until this threshold is reached, and then only if collateral blood supply is inadequate. ${ }^{10}$ Similarly, there must be a point beyond this critical stenosis where the lumen is so constricted and flow so minimal that the adequacy or inadequacy of collateral flow has already been established. Occlusion at this point would have 
no further haemodynamic effect.

Data from pathological examination of carotid plaques also suggest a critical threshold for symptoms. In the meticulous prospective study of Fisher and Ojemann, ${ }^{11}$ carotid plaques were removed intact at surgery and each specimen sectioned 1000-3000 times. Ischaemic cerebral symptoms were virtually confined to lumens of $1 \mathrm{~mm}$ or less $\left(80^{\circ}{ }_{0}\right.$ stenosis or more). The authors were so impressed by this threshold that they recommended "therapeutic intervention" in all patients with a demonstrated carotid stenosis of $1 \mathrm{~mm}$ or less, regardless of the occurrence of symptoms.

In our study, patients who became symptomatic from carotid ischaemic cerebral events had significantly more rapid progression of their arterial stenosis than those who remained asymptomatic. Rapidly progressing carotid stenoses more readily produce ischaemic cerebral symptoms $\mathrm{s}^{12-14}$ which may reflect the unstable morphology of the plaque. Large plaques which rapidly advance in size often consist of massive cholesterol-atheroma deposition $^{11}$ or recent, large intraplaque haemorrhage ${ }^{15}$, making them more friable and likely to embolise.

There are therapeutic implications to the concept of critical carotid stenosis in both symptomatic and asymptomatic patients. Stroke risk is negligible when the stenosis is below $75^{\circ}{ }^{4}$ after which point significant risk of cerebral ischaemia may occur from either haemodynamic or embolic causes. This should represent a therapeutic decision-making point for medical or surgical management. Once the stenosis progresses to levels over about $90^{\circ}{ }_{0}$ the threat to the cerebral circulation rapidly lessens and becomes negligible once the artery occludes; the therapeutic opportunity is over and collateral blood supply has proven itself adequate. This "window" becomes all the more vital if there is evidence of rapid progression of the carotid lesion, demonstrated by invasive or non-invasive carotid imaging in arteries with less than $75^{\circ}$ o stenosis.

We thank Mr Marco Katic for acting as statistical advisor, and Dr John Blakely for his helpful advice and criticism of our methodology.

1 Fisher CM. Occlusion of the internal carotid artery. Arch Neurol Psychiat 1951;65:346-77.

2 Hennerici M, Hulsbomer HB, Hefter H, Lammerts D, Rautenberg $W$. Natural history of asymptomatic extracranial arterial disease. Brain 1987;1 10:777-91.

3 Busuttil RW, Baker JD, Davidson RK, et al. Carotid artery stenosis-hemodynamic significance and clinical course. stenosis-hemodynamic signif
$J A M A$ 1982;245:1438-41.

4 Chambers BR, Norris JW. Outcome of patients with asymptomatic neck bruits. N Engl J Med 1986;315:860-5

5 Bornstein NM, Norris JW. Benign outcome of carotid occlusion. Neurology 1989;39:6-8.

6 D'Alton JG, Norris JW. Carotid Doppler evaluation in cerebrovascular disease. Can Med Assoc J 1983;129: $1184-9$.

7 Bornstein NM, Chadwick LG, Norris JW. The value of carotid Doppler ultresound in asymptomatic extracranial arterial disease. Can J Neurol Sci 1988;15:4, 1-6.

8 Sackett DL, Haynes BR, Tugwell P. Clinical Epidemiology. A basic science for clinical medicine. Little, Brown, Boston. Toronto, 1985 .

9 Spencer MW, Reid JM. Quantitation or carotid stenosis with continuous-wave (C-W) Doppler ultrasound. Stroke $1979 ; 10: 326-30$.

10 Fleming JRF, Deck JHN, Gotlieb AI. Pathology of atherosclerotic plaques. In: Smith RR ed. Stroke and the extracranial vessels. Raven Press, New York, 1984:23-37.

11 Fisher CM, Ojemann RG. A clinico-pathologic study of carotid endarterectomy plaques. Rev Neurol (Paris) 1986;142:573-89.

12 Hennerici $M$, Rautenberg $W$, Trockel U, Kladetzky RG. Spontaneous progression and regression of small carotid atheroma. Lancet $1985 ; i: 1415-9$.

13 Roederer GO, Langlois YE, Jager KA, et al. The natural history of carotid arterial disease in asymptomatic patients with cervical bruits. Stroke 1984;15:605-13.

14 Norris JW, Bornstein NM. Progression and regression of carotid stenosis. Stroke 1986:755-7.

15 Imparato AM, Riles TS, Gorstein F. The carotid bifurcation plaque; pathologic findings associated with cerebral
tion ischemia. Stroke 1979;10:238-45. 